Acta Crystallographica Section C

Crystal Structure

Communications

ISSN 0108-2701

\section{Four substituted benzohydrazides: hydrogen-bonded structures in one, two and three dimensions}

\author{
Solange M. S. V. Wardell, ${ }^{\mathrm{a}}$ Thatyana R. A. Vasconcelos, ${ }^{\mathrm{a}}$ \\ Marcus V. N. de Souza, ${ }^{a}$ James L. Wardell, ${ }^{b}$ John N. Low \\ and Christopher Glidewell ${ }^{\mathrm{d} *}$
}

anstituto de Tecnologia em Fármacos, Far-Manguinhos, FIOCRUZ, 21041-250 Rio de Janeiro, RJ, Brazil, ' Instituto de Química, Departamento de Química Inorgânica, Universidade Federal do Rio de Janeiro, CP 68563, 21945-970 Rio de Janeiro, RJ, Brazil, 'Department of Chemistry, University of Aberdeen, Meston Walk, Old Aberdeen AB24 3UE, Scotland, and ' School of Chemistry, University of St Andrews, Fife KY16 9ST, Scotland

Correspondence e-mail: cg@st-andrews.ac.uk

Received 16 August 2006

Accepted 30 August 2006

Online 21 September 2006

The molecules of 2,6-dichlorobenzohydrazide, $\mathrm{C}_{7} \mathrm{H}_{6} \mathrm{Cl}_{2} \mathrm{~N}_{2} \mathrm{O}$, are linked into simple chains by a single $\mathrm{N}-\mathrm{H} \cdots \mathrm{O}$ hydrogen bond, while in the isomeric compound 2,4-dichlorobenzohydrazide, the molecules are linked by $\mathrm{N}-\mathrm{H} \cdots \mathrm{N}$ and $\mathrm{N}-$ $\mathrm{H}$... O hydrogen bonds into complex sheets comprising an inner polar layer sandwiched between two non-polar layers. In 4-amino-2-chlorobenzohydrazide monohydrate, $\mathrm{C}_{7} \mathrm{H}_{8} \mathrm{ClN}_{3} \mathrm{O}$-$\mathrm{H}_{2} \mathrm{O}$, the components are linked into a three-dimensional framework by a combination of $\mathrm{O}-\mathrm{H} \cdots \mathrm{O}, \mathrm{O}-\mathrm{H} \cdots \mathrm{N}, \mathrm{N}-$ $\mathrm{H} \cdots \mathrm{N}$ and $\mathrm{N}-\mathrm{H} \cdots \mathrm{O}$ hydrogen bonds, and in 2-nitrobenzohydrazide, $\mathrm{C}_{7} \mathrm{H}_{7} \mathrm{~N}_{3} \mathrm{O}_{3}$, a three-dimensional framework is formed by a combination of $\mathrm{N}-\mathrm{H} \cdots \mathrm{N}$ and $\mathrm{N}-\mathrm{H} \cdots \mathrm{O}$ hydrogen bonds

\section{Comment}

As part of our general study of the supramolecular structures of amine and hydrazine derivatives, we report here the molecular and supramolecular structures of four related benzohydrazides, namely isomeric 2,6-dichlorobenzohydrazide, (I), and 2,4-dichlorobenzohydrazide, (II), 4-amino-2-chlorobenzohydrazide, which crystallizes as a monohydrate, (III), and 2-nitrobenzohydrazide, (IV). Compounds (I) and (II) were prepared straightforwardly by reaction of hydrazine with the methyl esters $\mathrm{ArCOOCH}_{3}$ to yield the corresponding hydrazines $\mathrm{ArCONHNH}$. By contrast, compound (III) was obtained, on one occasion only, from the reaction of hydrazine with methyl 2-chloro-4-fluorobenzoate; this reaction involves a nucleophilic displacement of the 4-fluoro substituent, and despite a number of attempts to reproduce this synthesis, we have been consistently unsuccessful.
The coordination at atoms $\mathrm{C} 7$ and N1 is effectively planar in each of compounds (I)-(IV) (Figs. 1-4), but the C1/C7/O1/N1/ $\mathrm{N} 2$ planes make dihedral angles with the aryl rings of $78.0(2)^{\circ}$ in (I), $38.5(2)^{\circ}$ in (II), 63.9 (2) $)^{\circ}$ in (III) and 42.9 (2) in (IV). However, the orientations of the side chains differ markedly between compounds (II) and (III), with atom N1 syn to $\mathrm{Cl} 2$ in (II) but anti in (III) (Figs. 2 and 3).<smiles>NNC(=O)c1c(Cl)cccc1Cl</smiles>

(I)<smiles>NNC(=O)c1ccc(Cl)cc1Cl</smiles>

(II)<smiles>NNC(=O)c1ccc(N)cc1Cl</smiles>

(III)<smiles>NNC(=O)c1ccccc1[N+](=O)[O-]</smiles>

(IV)<smiles>NNC(=O)c1ccc(Cl)cc1</smiles>

(V)<smiles>NNC(=O)c1ccccc1</smiles>

(VI)<smiles>NNC(=O)c1cccc([N+](=O)[O-])c1</smiles>

(VII)
The exocyclic bond angles in compound (II) show some significant variations, including significant deviations from the idealized values of $120^{\circ}$ (Table 5). Thus, although the two independent exocyclic angles at atom $\mathrm{C} 4$ are identical within experimental uncertainty, those at atom $\mathrm{C} 2$ differ by more than $5^{\circ}$, while those at $\mathrm{C} 1$ differ by some $12^{\circ}$. The sense of these deviations suggests strongly repulsive interactions between atoms $\mathrm{Cl} 2$ and $\mathrm{C} 7$ and/or N1, possibly associated with

\section{Figure 1}

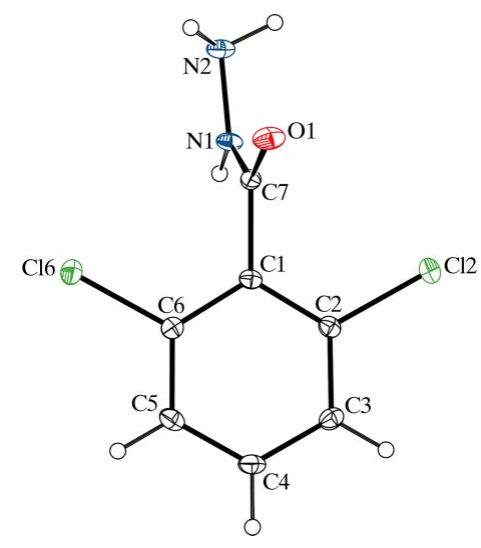

A molecule of (I), with the atom-labelling scheme shown. Displacement ellipsoids are drawn at the $30 \%$ probability level. 
the rather short intramolecular $\mathrm{H} 1 \cdots \mathrm{Cl} 2$ contact in (II) (Table 2). By contrast, the corresponding angles in compounds (I) and (III), where there are no short intramolecular contacts involving atom $\mathrm{Cl} 2$ (or $\mathrm{Cl} 6$ ), show no such features, while any such effect in compound (IV) is very modest in magnitude.

In each compound, the coordination of hydrazine atom N2 is sharply pyramidal (Figs. 1-4), with sums of angles at N2 consistently less than $330^{\circ}$. In addition, amino atom N4 in compound (III) is pyramidal, and the $\mathrm{C} 4-\mathrm{N} 4$ distance [1.395 (2) $\AA$ ] is identical to the mean values for $\mathrm{C}($ aryl $)-\mathrm{NH}_{2}$ bonds with pyramidal $\mathrm{N}$ atoms and much longer than the corresponding mean value $(1.355 \AA)$ for such bonds with planar $\mathrm{N}$ atoms (Allen et al., 1987).

In compound (I), the molecules are linked into simple chains by a single $\mathrm{N}-\mathrm{H}$. . O hydrogen bond (Table 1). Atom $\mathrm{N} 1$ in the molecule at $(x, y, z)$ acts as a hydrogen-bond donor to atom $\mathrm{O} 1$ in the molecule at $\left(\frac{1}{2}+x, \frac{3}{2}-y, \frac{1}{2}+z\right)$, so forming a

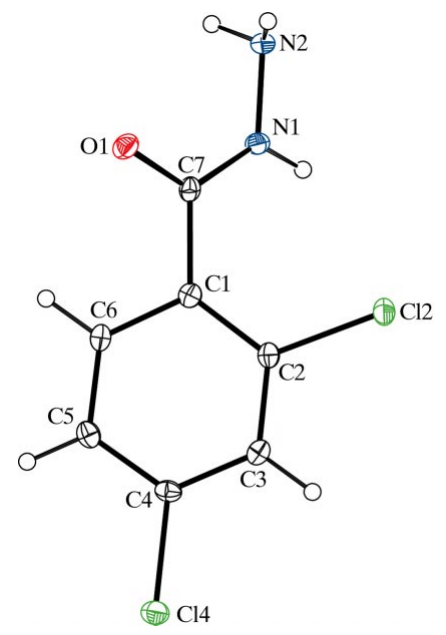

Figure 2

A molecule of (II), with the atom-labelling scheme shown. Displacement ellipsoids are drawn at the $30 \%$ probability level.

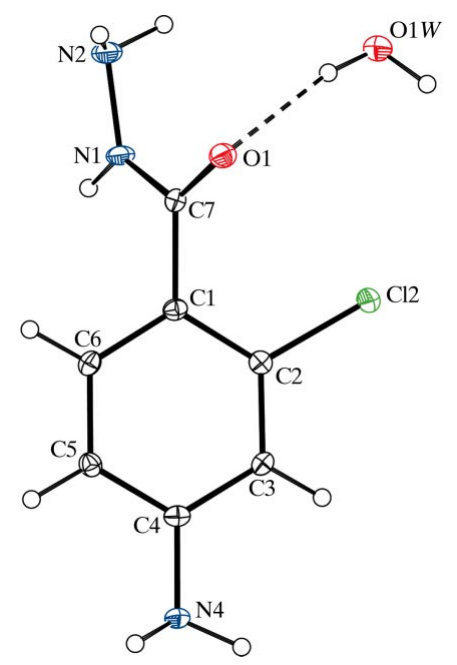

Figure 3

The independent molecular components in (III), with the atom-labelling scheme shown. Displacement ellipsoids are drawn at the $30 \%$ probability level.
C(4) (Bernstein et al., 1995) chain running parallel to the [101] direction and generated by the $n$-glide plane at $y=\frac{3}{4}$ (Fig. 5). Two such chains, related to one another by inversion and hence antiparallel, pass through each unit cell, but there are no direction-specific interactions between adjacent chains. It is notable that the $\mathrm{NH}_{2}$ group in compound (I) plays no part in the supramolecular aggregation; there are no potential donor or acceptor atoms of any type within hydrogen-bonding range.

The molecules of (II) are linked by a combination of one $\mathrm{N}-\mathrm{H} \cdots \mathrm{N}$ hydrogen bond and two $\mathrm{N}-\mathrm{H} \cdots \mathrm{O}$ hydrogen bonds (Table 2) into sheets whose formation is readily analysed in terms of two simple substructures. In the first of these substructures, paired $\mathrm{N}-\mathrm{H} \cdots \mathrm{N}$ hydrogen bonds link the molecules at $(x, y, z)$ and $(1-x, 1-y, 1-z)$ into centrosymmetric $R_{2}^{2}(6)$ (Bernstein et al., 1995) dimers (Fig. 6). The second substructure is formed by the two $\mathrm{N}-\mathrm{H} \cdots \mathrm{O}$ hydrogen bonds; atom $\mathrm{N} 2$ in the molecule at $(x, y, z)$ acts as a hydrogen-bond donor, via $\mathrm{H} 2 A$ and $\mathrm{H} 2 B$, respectively, to

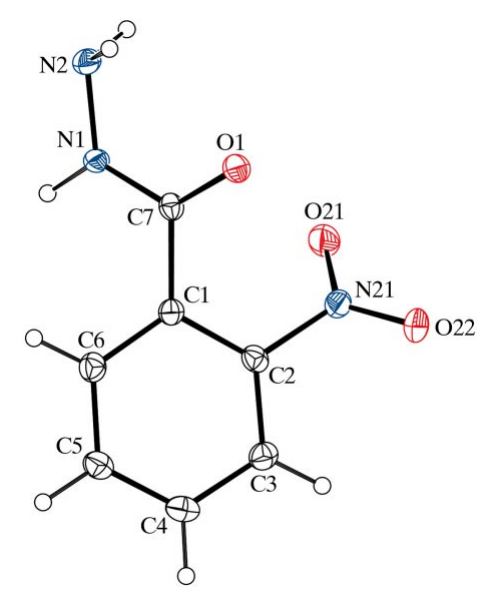

Figure 4

A molecule of (IV), with the atom-labelling scheme shown. Displacement ellipsoids are drawn at the $30 \%$ probability level.

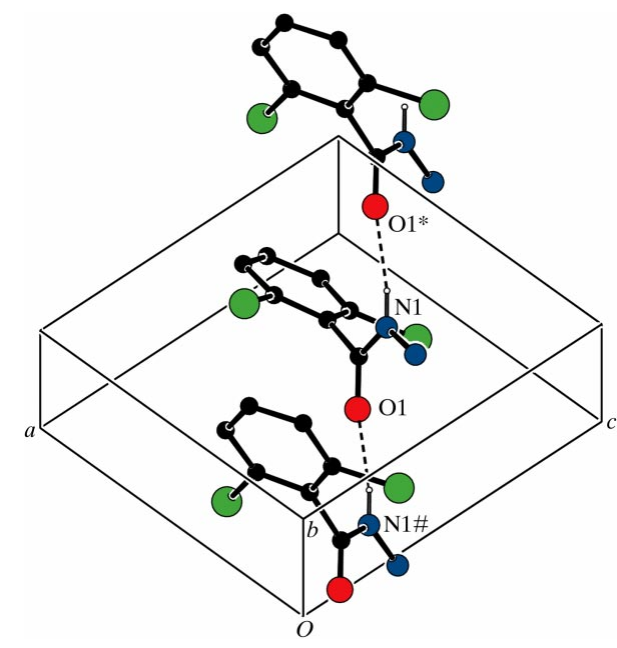

Figure 5

Part of the crystal structure of (I), showing the formation of a $C(4)$ chain along [101]. For the sake of clarity, $\mathrm{H}$ atoms not involved in the motif shown have been omitted. Atoms marked with an asterisk (*) or a hash (\#) are at the symmetry positions $\left(\frac{1}{2}+x, \frac{3}{2}-y, \frac{1}{2}+z\right)$ and $\left(-\frac{1}{2}+x, \frac{3}{2}-y\right.$, $\left.-\frac{1}{2}+z\right)$, respectively. 
atoms $\mathrm{O} 1$ in the molecules at $\left(1-x, \frac{1}{2}+y, \frac{3}{2}-z\right)$ and $(1-x$, $\left.-\frac{1}{2}+y, \frac{3}{2}-z\right)$, respectively, so forming a chain of edge-fused $R_{2}^{2}(10)$ rings running parallel to the [010] direction and generated by the $2_{1}$ screw axis along $\left(\frac{1}{2}, y, \frac{3}{4}\right)$ (Fig. 7). The combination of the finite zero-dimensional substructure (Fig. 2) and the one-dimensional substructure (Fig. 3) then leads to the formation of thick tripartite sheets, parallel to (100), in which a central polar layer is sandwiched between two non-polar layers with $\mathrm{Cl}$ atoms on the exterior faces (Fig. 8).

The molecules of (III) are linked into a three-dimensional framework structure by a combination of $\mathrm{O}-\mathrm{H} \cdots \mathrm{O}$, O$\mathrm{H} \cdots \mathrm{N}, \mathrm{N}-\mathrm{H} \cdots \mathrm{N}$ and $\mathrm{N}-\mathrm{H} \cdots \mathrm{O}$ hydrogen bonds (Table 3 ). The organic components are linked into sheets by one $\mathrm{N}-$ $\mathrm{H} \cdots \mathrm{N}$ and one $\mathrm{N}-\mathrm{H} \cdots \mathrm{O}$ interaction, and these sheets are linked into a continuous framework by means of the water

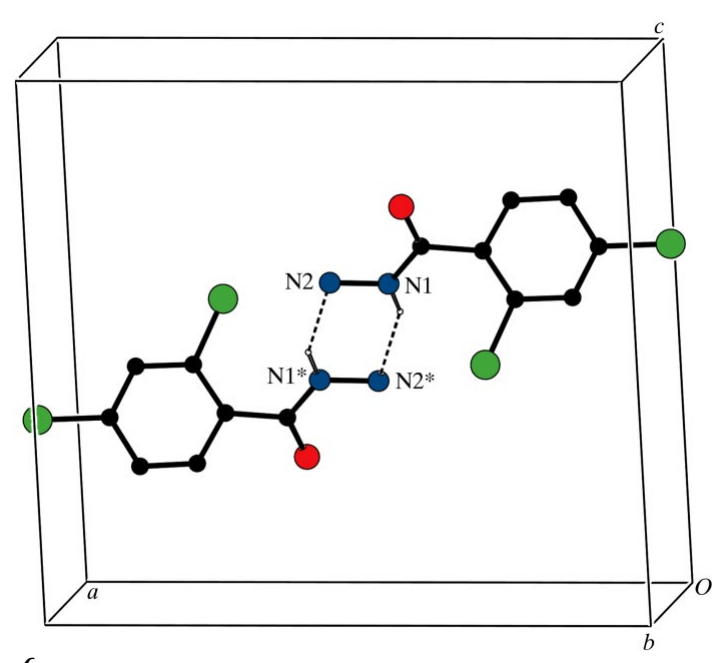

Figure 6

Part of the crystal structure of (II), showing the formation of a centrosymmetric $R_{2}^{2}(6)$ dimer. For the sake of clarity, $\mathrm{H}$ atoms not involved in the motif shown have been omitted. Atoms marked with an asterisk $(*)$ are at the symmetry position $(1-x, 1-y, 1-z)$.

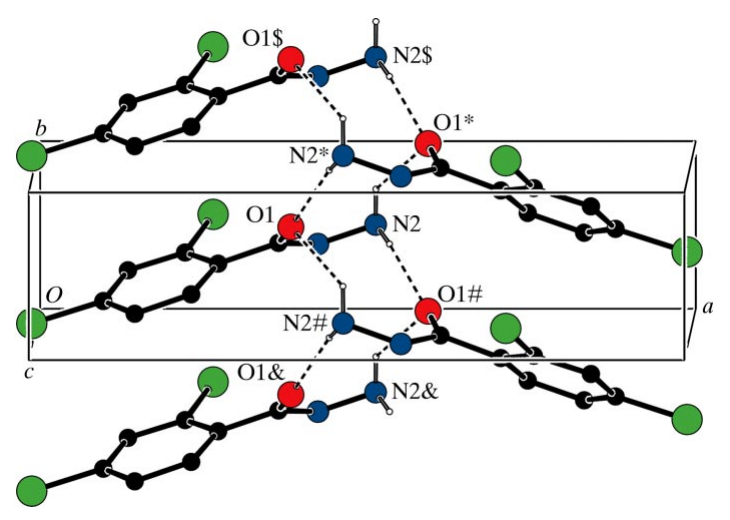

Figure 7

Part of the crystal structure of (II), showing the formation of a [010] chain of edge-fused $R_{2}^{2}(10)$ rings. For the sake of clarity, $\mathrm{H}$ atoms not involved in the motif shown have been omitted. Atoms marked with an asterisk $(*)$, a hash (\#), a dollar sign (\$) or an ampersand (\&) are at the symmetry positions $\left(1-x, \frac{1}{2}+y, \frac{3}{2}-z\right),\left(1-x,-\frac{1}{2}+y, \frac{3}{2}-z\right),(x, 1+y, z)$ and $(x,-1+y, z)$, respectively. molecules. Paired $\mathrm{N}-\mathrm{H} \cdots \mathrm{N}$ hydrogen bonds link the organic molecules into centrosymmetric $R_{2}^{2}(16)$ dimers (Fig. 9), and the reference dimer centred at $\left(\frac{1}{2}, \frac{1}{2}, \frac{1}{2}\right)$ is linked by $\mathrm{N}-\mathrm{H} \cdots \mathrm{O}$ hydrogen bonds to four similar dimers centred at $\left(\frac{1}{2}, 0,0\right)$, $\left(\frac{1}{2}, 0,1\right),\left(\frac{1}{2}, 1,0\right)$ and $\left(\frac{1}{2}, 1,1\right)$, thereby generating a (100) sheet built from $R_{2}^{2}(16)$ and $R_{6}^{6}(28)$ rings alternating in a chessboard fashion (Fig. 9).

The simplest description of the linking of the (100) sheets is in terms of one each of $\mathrm{O}-\mathrm{H} \cdots \mathrm{O}$ and $\mathrm{N}-\mathrm{H} \cdots \mathrm{O}$ hydrogen bonds. The $\mathrm{O}-\mathrm{H} \cdots \mathrm{O}$ hydrogen bond lies within the selected asymmetric unit (Fig. 3); in addition, atom $\mathrm{N} 4$ at $(x, y, z)$ acts as a donor to water atom $\mathrm{O} 1 W$ at $\left(-1+x, \frac{3}{2}-y,-\frac{1}{2}+z\right)$, so forming a $C_{2}^{2}(10)$ chain running parallel to the [201] direction and generated by the $c$-glide plane at $y=0.75$ (Fig. 10).
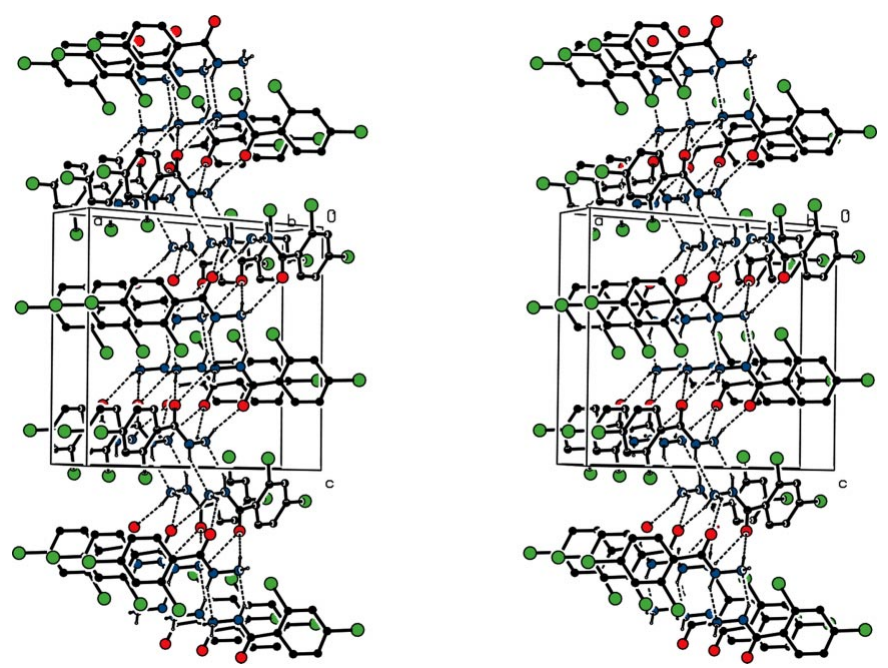

Figure 8

A stereoview of part of the crystal structure of (II), showing the formation of a (100) sheet. For the sake of clarity, $\mathrm{H}$ atoms bonded to $\mathrm{C}$ atoms have been omitted.
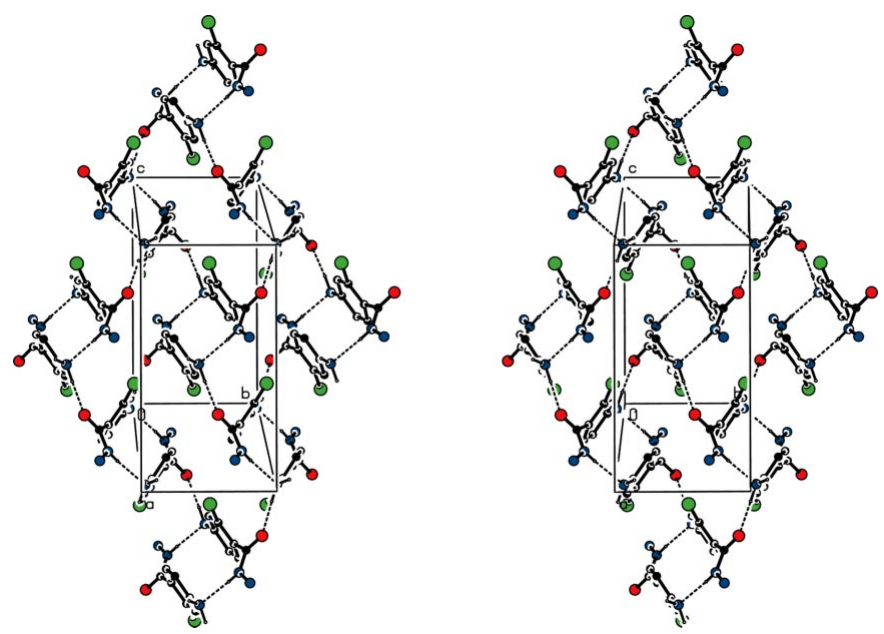

Figure 9

A stereoview of part of the crystal structure of (III), showing the formation of a (100) sheet built from organic molecules only. For the sake of clarity, $\mathrm{H}$ atoms bonded to $\mathrm{C}$ or $\mathrm{N}$ atoms not involved in the motif shown have been omitted. 
In (IV), the molecules are linked by a combination of $\mathrm{N}-$ $\mathrm{H} \cdot \mathrm{OO}$ and $\mathrm{N}-\mathrm{H} \cdots \mathrm{N}$ hydrogen bonds (Table 4) into a threedimensional framework whose formation is readily analysed in terms of three one-dimensional substructures.

In the simplest of these substructures, which depends on the action of just one hydrogen bond, atom $\mathrm{N} 2$ in the molecule at $(x, y, z)$ acts as a hydrogen-bond donor, via $\mathrm{H} 2 A$, to nitro atom $\mathrm{O} 22$ in the molecule at $\left(-\frac{1}{2}+x, \frac{1}{2}-y, 1-z\right)$, so forming a simple $C(8)$ chain running parallel to the [100] direction and generated by the $2_{1}$ screw axis along $\left(x, \frac{1}{4}, \frac{1}{2}\right)$ (Fig. 11). A second substructure is formed by the concerted action of the other two hydrogen bonds. Atom $\mathrm{N} 2$ in the molecule at $(x, y$, $z$ ) acts as a hydrogen-bond donor to atom N2 in the molecule at $\left(1-x,-\frac{1}{2}+y, \frac{1}{2}-z\right)$, so forming a $C(2)$ chain running parallel to the [010] direction and generated by the $2_{1}$ screw axis along $\left(\frac{1}{2}, y, \frac{1}{4}\right)$. At the same time, atom $\mathrm{N} 1$ in the molecule at $(x, y, z)$ acts as a donor to carbonyl atom $\mathrm{O} 1$ in the molecule at $(x, 1+y, z)$, so generating by translation a $C(4)$ chain along [010], and the combination of the two [010] chains generates a chain of edge-fused $R_{3}^{3}(10)$ rings (Fig. 12). Finally, the combination of the two hydrogen bonds formed by the $\mathrm{NH}_{2}$ group generates a $C_{2}^{2}(10)$ chain running parallel to the [001] direction (Fig. 13). The combination of [100], [010] and [001] chains then generates a single three-dimensional framework.

It is of interest briefly to compare the supramolecular structures of the compounds reported here with those of some

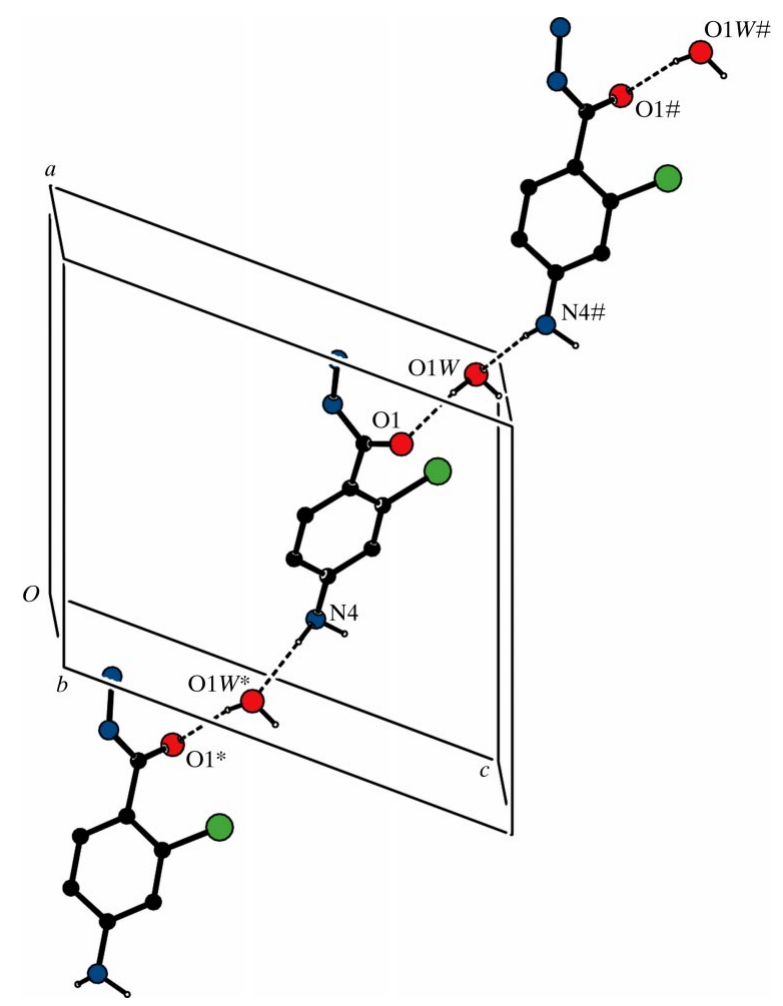

Figure 10

Part of the crystal structure of (III), showing the formation of a $C_{2}^{2}(10)$ chain along [201]. For the sake of clarity, $\mathrm{H}$ atoms bonded to $\mathrm{C}$ or $\mathrm{N}$ atoms not involved in the motif shown have been omitted. Atoms marked with an asterisk $(*)$ or a hash (\#) are at the symmetry positions $\left(-1+x, \frac{3}{2}-y\right.$, $\left.-\frac{1}{2}+z\right)$ and $\left(1+x, \frac{3}{2}-y, \frac{1}{2}+z\right)$, respectively.

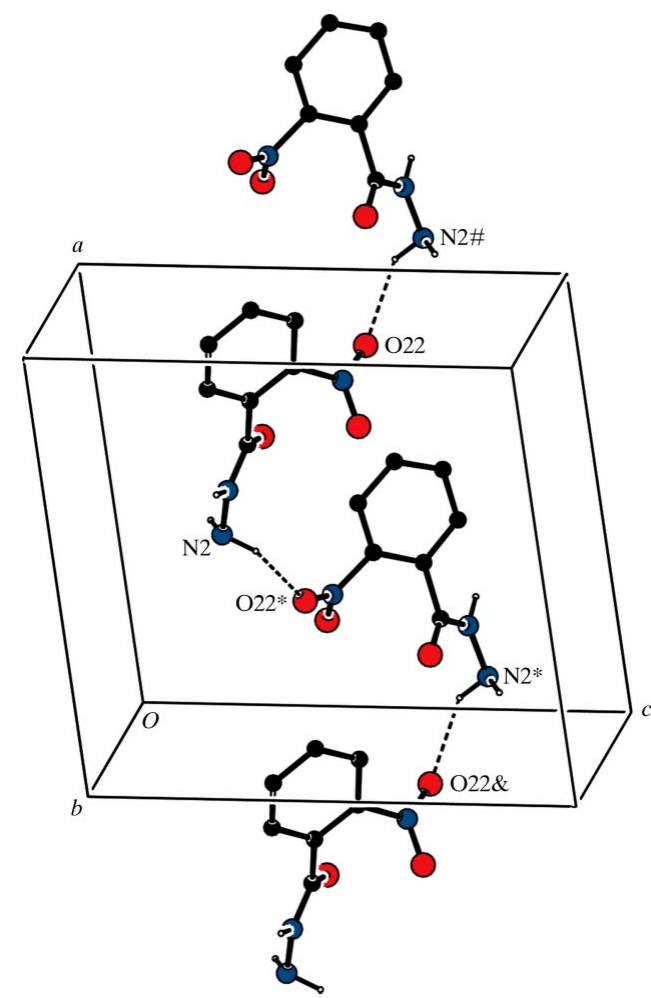

Figure 11

Part of the crystal structure of (IV), showing the formation of a $C(8)$ chain along [100]. For the sake of clarity, $\mathrm{H}$ atoms bonded to $\mathrm{C}$ atoms have been omitted. Atoms marked with an asterisk (*), a hash (\#) or an ampersand $(\&)$ are at the symmetry positions $\left(-\frac{1}{2}+x, \frac{1}{2}-y, 1-z\right)$, $\left(\frac{1}{2}+x, \frac{1}{2}-y, 1-z\right)$ and $(-1+x, y, z)$, respectively.

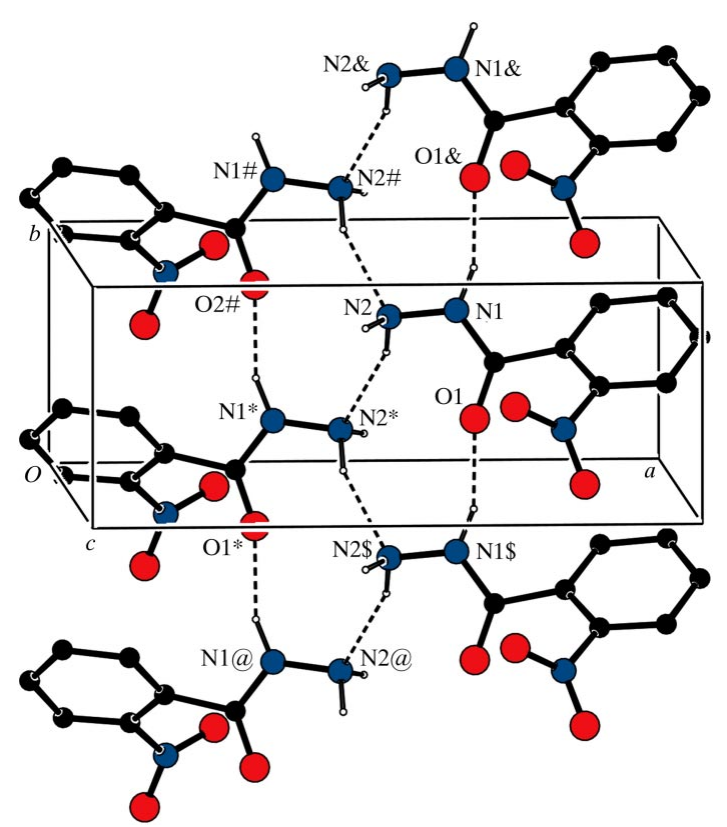

Figure 12

Part of the crystal structure of (IV), showing the formation of a chain of edge-fused $R_{3}^{3}(10)$ rings along [010]. For the sake of clarity, $\mathrm{H}$ atoms bonded to $\mathrm{C}$ atoms have been omitted. Atoms marked with an asterisk $(*)$, a hash (\#), a dollar sign (\$), an ampersand (\&) or an 'at' sign (@) are at the symmetry positions $\left(1-x,-\frac{1}{2}+y, \frac{1}{2}-z\right),\left(1-x,-\frac{1}{2}+y, \frac{1}{2}-z\right)$, $(x,-1+y, z),(x, 1+y, z)$ and $\left(1-x,-\frac{3}{2}+y, \frac{1}{2}-z\right)$, respectively. 
closely related analogues from the literature. A very brief report on the 4-chloro analogue, $(\mathrm{V})$, stated that the structure is held together by two hydrogen bonds, one each of $\mathrm{N}-$ $\mathrm{H} \cdots \mathrm{N}$ and $\mathrm{N}-\mathrm{H} \cdots \mathrm{O}$ types (Saraogi et al., 2002). While no discussion of the aggregation was given, the packing diagram provided appears to show a chain of edge-fused rings along [100]. However, re-examination of the structure using the published atomic coordinates shows that there are, in fact, three intermolecular hydrogen bonds present, one of $\mathrm{N}-$ $\mathrm{H} \cdots \mathrm{N}$ type and two of $\mathrm{N}-\mathrm{H} \cdots \mathrm{O}$ type, and these link the molecules into complex sheets parallel to (100) in which all the Cl substituents lie on the two faces of the sheet (Fig. 14), so

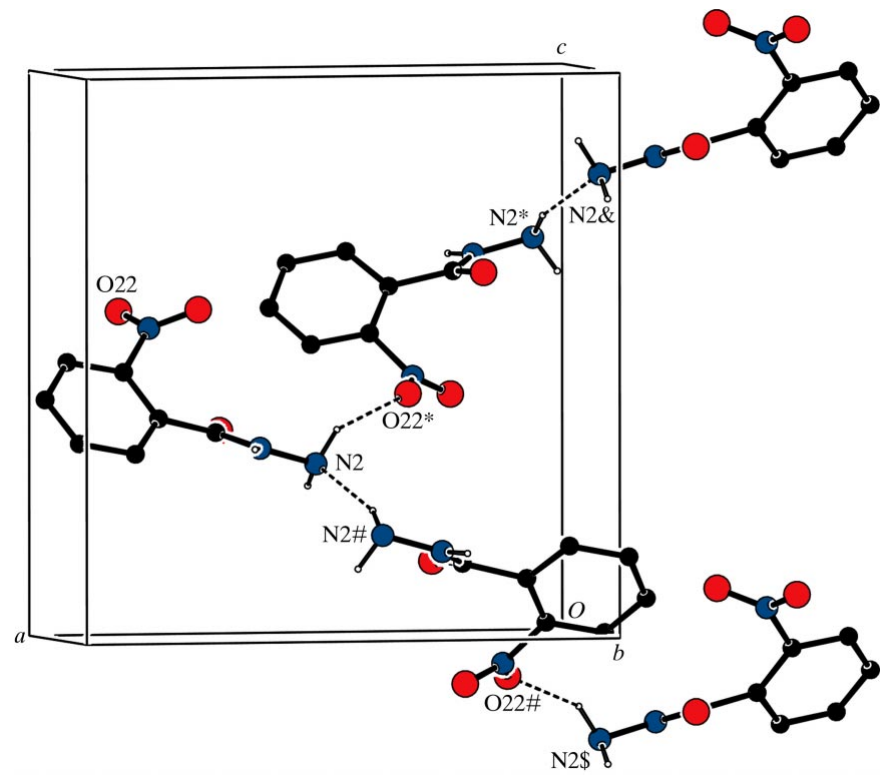

Figure 13

Part of the crystal structure of (IV), showing the formation of a $C_{2}^{2}(10)$ chain along [100]. For the sake of clarity, $\mathrm{H}$ atoms bonded to $\mathrm{C}$ atoms have been omitted. Atoms marked with an asterisk (*), a hash (\#), a dollar sign (\$) or an ampersand $(\&)$ are at the symmetry positions $\left(-\frac{1}{2}+x\right.$, $\left.\frac{1}{2}-y, 1-z\right),\left(1-x, \frac{1}{2}+y, \frac{1}{2}-z\right),\left(\frac{1}{2}-x, 1-y,-\frac{1}{2}+z\right)$ and $\left(\frac{1}{2}-x, 1-y\right.$, $\left.\frac{1}{2}+z\right)$, respectively.
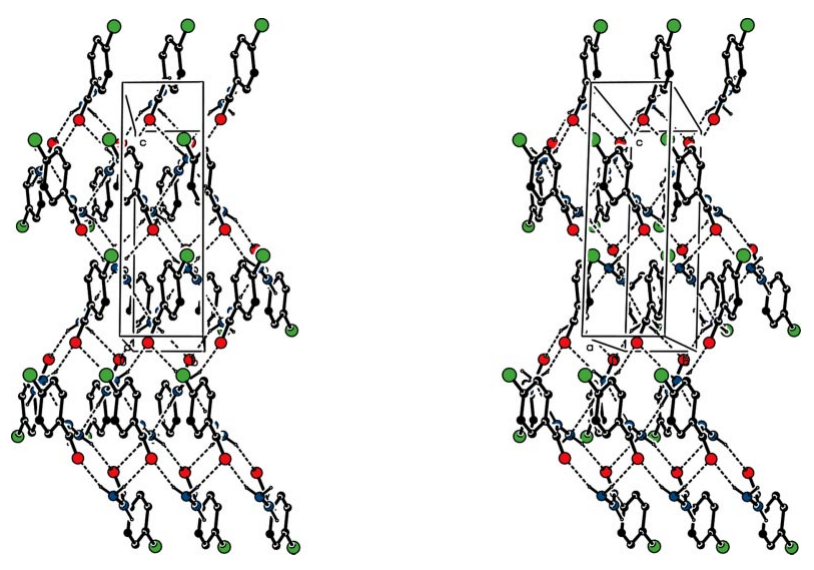

Figure 14

A stereoview of part of the crystal structure of $(\mathrm{V})$, showing the formation of a sheet parallel to (100). The original atom coordinates (Saraogi et al., 2002) have been used. For the sake of clarity, $\mathrm{H}$ atoms bonded to $\mathrm{C}$ atoms have been omitted. that there are no direction-specific interactions between these sheets. Even the two hydrogen bonds listed in the original report (Saraogi et al., 2002) suffice to generate this type of (100) sheet. For the unsubstituted compound (VI), there is again only a very brief report with no discussion of the supramolecular aggregation (Kallel et al., 1992). Again, reexamination of the structure using coordinates as retrieved from the Cambridge Structural Database (Allen, 2002; refcode VOPJEP) shows that this compound forms exactly the same type of (100) sheet as the 4-chloro analogue (V), and that it is, indeed, isomorphous and effectively isostructural with compound $(\mathrm{V})$, although this fact was not noted in the report on (V) (Saraogi et al., 2002). In compound (VII), which is isomeric with (IV), the molecules are linked into a threedimensional framework of some complexity, built from a combination of $\mathrm{N}-\mathrm{H} \cdots \mathrm{O}, \mathrm{N}-\mathrm{H} \cdots \mathrm{N}, \mathrm{C}-\mathrm{H} \cdots \mathrm{O}$ and $\mathrm{C}-$ $\mathrm{H} \cdots \mathrm{N}$ hydrogen bonds (Ratajczak et al., 2001).

The supramolecular structures discussed here show the marked effects on the aggregation of the identity of the substituents on the aryl ring and, in the case of the pairs of isomers (I)/(II) and (IV)/(VII) the strong influence of the orientation of the substituents, even when, as in (I) and (II), they play no direct role in the aggregation.

\section{Experimental}

A commercial sample (Aldrich) of compound (IV) was recrystallized from ethanol. For the synthesis of compounds (I)-(III), a solution of the appropriate methyl ester [methyl 2,6-dichlorobenzoate for (I), methyl 2,4-dichlorobenzoate for (II) and methyl 2-chloro-4-fluorobenzoate for (III)] and a fivefold molar excess of hydrazine hydrate in methanol was held at $353 \mathrm{~K}$ for $6-8 \mathrm{~h}$. The mixtures were concentrated to dryness under reduced pressure, and the resulting solid products (I)-(III) were purified by washing successively with cold ethanol and diethyl ether, providing crystalline material suitable for single-crystal X-ray diffraction. (I): yield 71\%, m.p. 415-417 K; NMR $\left(\mathrm{DMSO}-d_{6}\right): \delta(\mathrm{H}) 9.74(1 \mathrm{H}, s, \mathrm{NH}), 7.50(2 \mathrm{H}, d, J=8.0 \mathrm{~Hz}, \mathrm{H} 3$ and H5), $7.44(1 \mathrm{H}, t, J=8.0 \mathrm{~Hz}, \mathrm{H} 4), 4.63\left(2 \mathrm{H}, s, \mathrm{NH}_{2}\right) ; \delta(\mathrm{C}) 162.8,135.4$, 131.7, 131.2, 128.1; IR ( $\mathrm{KBr}$ disk, $\left.\mathrm{cm}^{-1}\right)$ : 3312-3271 $\left(\mathrm{NH}_{2}\right), 3209$ (NH), 1644 (CO). (II): yield 66\%, m.p. 413-414 K; NMR (DMSO- $d_{6}$ ): $\delta(\mathrm{H}) 9.63(1 \mathrm{H}, s, \mathrm{NH}), 7.69(1 \mathrm{H}, d, J=1.0 \mathrm{~Hz}, \mathrm{H} 3), 7.49(1 \mathrm{H}, d d, J=$ 1.0 and $8.0 \mathrm{~Hz}, \mathrm{H} 5), 7.42(1 \mathrm{H}, d, J=8.0 \mathrm{~Hz}, \mathrm{H} 6), 4.55\left(2 \mathrm{H}, s, \mathrm{NH}_{2}\right)$; $\delta(\mathrm{C}) 164.7,134.5,134.4,131.5,130.4,129.1,127.2$; IR (KBr disk, $\left.\mathrm{cm}^{-1}\right)$ : 3310-3273 $\left(\mathrm{NH}_{2}\right), 3211(\mathrm{NH}), 1646(\mathrm{CO})$. (III): yield $70 \%$, m.p. 446-447 K: NMR (DMSO- $\left.d_{6}\right): \delta(\mathrm{H}) 9.58(1 \mathrm{H}, s, \mathrm{NH}), 7.94(1 \mathrm{H}$, $d, J=7.9 \mathrm{~Hz}, \mathrm{H} 6), 7.65(1 \mathrm{H}, d, J=1.0 \mathrm{~Hz}, \mathrm{H} 3), 6.92(1 \mathrm{H}, d d, J=1.0$ and $7.9 \mathrm{~Hz}, \mathrm{H} 5), 7.21\left(2 \mathrm{H}, s, \mathrm{NH}_{2}\right), 4.25\left(2 \mathrm{H}, s, \mathrm{NH}_{2}\right) ; \delta(\mathrm{C}) 164.5$, 142.3, 132.1, 127.3, 126.7, 117.1, 111.2; IR ( $\mathrm{KBr}$ disk, $\left.\mathrm{cm}^{-1}\right)$ : 3313$3274\left(\mathrm{NH}_{2}\right), 3213(\mathrm{NH}), 1649(\mathrm{CO})$.

\section{Compound (I)}

\section{Crystal data}

$\mathrm{C}_{7} \mathrm{H}_{6} \mathrm{Cl}_{2} \mathrm{~N}_{2} \mathrm{O}$

$M_{r}=205.04$

Monoclinic, $P 2_{1} / n$

$a=7.5511(2) \AA$

$b=14.4834$ (4) ^

$c=8.3097$ (3) $\AA$

$\beta=110.485(2)^{\circ}$

$V=851.33(5) \AA^{3}$

$$
\begin{aligned}
& Z=4 \\
& D_{x}=1.600 \mathrm{Mg} \mathrm{m}^{-3} \\
& \text { Mo } K \alpha \text { radiation } \\
& \mu=0.71 \mathrm{~mm}^{-1} \\
& T=120(2) \mathrm{K} \\
& \text { Lath, colourless } \\
& 0.54 \times 0.36 \times 0.08 \mathrm{~mm}
\end{aligned}
$$




\section{organic compounds}

Data collection

Bruker-Nonius KappaCCD diffractometer

$\varphi$ and $\omega$ scans

Absorption correction: multi-scan (SADABS; Sheldrick, 2003)

$T_{\min }=0.700, T_{\max }=0.945$

10109 measured reflections

\section{Refinement}

Refinement on $F^{2}$ $R\left[F^{2}>2 \sigma\left(F^{2}\right)\right]=0.028$

$w R\left(F^{2}\right)=0.072$

$S=1.05$

1950 reflections

109 parameters

$\mathrm{H}$-atom parameters

constrained

Table 1

Hydrogen-bond geometry $\left(\AA,^{\circ}\right)$ for (I).

\begin{tabular}{lllll}
\hline$D-\mathrm{H} \cdots A$ & $D-\mathrm{H}$ & $\mathrm{H} \cdots A$ & $D \cdots A$ & $D-\mathrm{H} \cdots A$ \\
\hline $\mathrm{N} 1-\mathrm{H} 1 \cdots \mathrm{O} 1^{\mathrm{i}}$ & 0.85 & 1.98 & $2.8246(15)$ & 172
\end{tabular}

Symmetry code: (i) $x+\frac{1}{2},-y+\frac{3}{2}, z+\frac{1}{2}$.

\section{Compound (II)}

Crystal data

$\mathrm{C}_{7} \mathrm{H}_{6} \mathrm{Cl}_{2} \mathrm{~N}_{2} \mathrm{O}$

$M_{r}=205.04$

Monoclinic, $P 2_{1} / c$

$a=15.1188(17) \AA$

$b=3.8801$ (4) $\AA$

$c=13.6029(14) \AA$

$\beta=91.106(6)^{\circ}$

$V=797.83(15) \AA^{3}$

$$
\begin{aligned}
& w=1 /\left[\sigma^{2}\left(F_{\mathrm{o}}^{2}\right)+(0.035 P)^{2}\right. \\
& \quad+0.3426 P] \\
& \text { where } P=\left(F_{\mathrm{o}}^{2}+2 F_{\mathrm{c}}^{2}\right) / 3 \\
& (\Delta / \sigma)_{\max }<0.001 \\
& \Delta \rho_{\max }=0.35 \AA^{-3} \\
& \Delta \rho_{\min }=-0.26 \AA^{-3}
\end{aligned}
$$

independent reflections 661 reflections with $I>2 \sigma(I)$

\section{Data collection}

Bruker-Nonius KappaCCD diffractometer

$\varphi$ and $\omega$ scans

Absorption correction: multi-scan

(SADABS; Sheldrick, 2003)

$T_{\min }=0.794, T_{\max }=0.978$

8399 measured reflections

\section{Refinement}

Refinement on $F^{2}$

$R\left[F^{2}>2 \sigma\left(F^{2}\right)\right]=0.046$

$w R\left(F^{2}\right)=0.101$

$S=1.03$

1813 reflections

109 parameters

$\mathrm{H}$-atom parameters

constrained

$$
Z=4
$$

$D_{x}=1.707 \mathrm{Mg} \mathrm{m}^{-3}$

Mo $K \alpha$ radiation

$\mu=0.76 \mathrm{~mm}^{-1}$

$T=120$ (2) K

Plate, colourless

$0.32 \times 0.30 \times 0.03 \mathrm{~mm}$

1813 independent reflections 1327 reflections with $I>2 \sigma(I)$

$$
R_{\text {int }}=0.065
$$$$
\theta_{\max }=27.7^{\circ}
$$

\section{Table 2}

Hydrogen-bond geometry $\left(\AA,^{\circ}\right)$ for (II).

\begin{tabular}{lllll}
\hline$D-\mathrm{H} \cdots A$ & $D-\mathrm{H}$ & $\mathrm{H} \cdots A$ & $D \cdots A$ & $D-\mathrm{H} \cdots A$ \\
\hline $\mathrm{N} 1-\mathrm{H} 1 \cdots \mathrm{Cl} 2$ & 0.85 & 2.65 & $3.103(2)$ & 115 \\
$\mathrm{~N} 1-\mathrm{H} 1 \cdots \mathrm{N} 2^{\mathrm{i}}$ & 0.85 & 2.22 & $2.971(3)$ & 147 \\
$\mathrm{~N} 2-\mathrm{H} 2 A \cdots \mathrm{O} 1^{\mathrm{ii}}$ & 0.86 & 2.50 & $3.115(3)$ & 129 \\
$\mathrm{~N} 2-\mathrm{H} 2 B \cdots 1^{\mathrm{iii}}$ & 0.83 & 2.16 & $2.972(3)$ & 165 \\
\hline
\end{tabular}

Symmetry codes: (i) $-x+1,-y+1,-z+1$; (ii) $-x+1, y+\frac{1}{2},-z+\frac{3}{2}$; (iii) $-x+1$, $y-\frac{1}{2},-z+\frac{3}{2}$.

\section{Compound (III)}

Crystal data

$\mathrm{C}_{7} \mathrm{H}_{8} \mathrm{ClN}_{3} \mathrm{O} \cdot \mathrm{H}_{2} \mathrm{O}$

$M_{r}=203.63$

Monoclinic, $P 2_{1} / c$

$a=11.1667$ (4) $\AA$

$b=6.9936(3) \AA$

$c=12.7105(4) \AA$

$\beta=112.02(6)^{\circ}$

$V=920.2(4) \AA^{3}$

Data collection

Bruker-Nonius KappaCCD

diffractometer

$\varphi$ and $\omega$ scans

Absorption correction: multi-scan

(SADABS; Sheldrick, 2003)

$T_{\min }=0.874, T_{\max }=0.977$

\section{Refinement}

Refinement on $F^{2}$

$R\left[F^{2}>2 \sigma\left(F^{2}\right)\right]=0.035$

$w R\left(F^{2}\right)=0.091$

$S=1.06$

2113 reflections

121 parameters

$\mathrm{H}$-atom parameters constrained

$Z=4$

$D_{x}=1.470 \mathrm{Mg} \mathrm{m}^{-3}$

Mo $K \alpha$ radiation

$\mu=0.39 \mathrm{~mm}^{-1}$

$T=120$ (2) K

Lath, yellow

$0.36 \times 0.18 \times 0.06 \mathrm{~mm}$

10045 measured reflections 2113 independent reflections 1700 reflections with $I>2 \sigma(I)$ $R_{\text {int }}=0.039$

$\theta_{\max }=27.5^{\circ}$

$w=1 /\left[\sigma^{2}\left(F_{\mathrm{o}}^{2}\right)+(0.0431 P)^{2}\right.$ $+0.3314 P]$

where $P=\left(F_{\mathrm{o}}^{2}+2 F_{\mathrm{c}}^{2}\right) / 3$

$(\Delta / \sigma)_{\max }=0.001$

$\Delta \rho_{\max }=0.25 \mathrm{e}^{-3}$

$\Delta \rho_{\min }=-0.29 \mathrm{e} \AA^{-3}$

Table 3

Hydrogen-bond geometry $\left(\AA,^{\circ}\right)$ for (III).

\begin{tabular}{lllll}
\hline$D-\mathrm{H} \cdots A$ & $D-\mathrm{H}$ & $\mathrm{H} \cdots A$ & $D \cdots A$ & $D-\mathrm{H} \cdots A$ \\
\hline $\mathrm{O} 1 W-\mathrm{H} 1 W \cdots \mathrm{O} 1$ & 0.84 & 1.99 & $2.822(2)$ & 169 \\
$\mathrm{O} 1 W-\mathrm{H} 2 W \cdots \mathrm{N} 2^{\mathrm{i}}$ & 0.87 & 2.01 & $2.871(2)$ & 170 \\
$\mathrm{~N} 1-\mathrm{H} 1 \cdots \mathrm{N} 4^{\mathrm{ii}}$ & 0.83 & 2.15 & $2.978(2)$ & 173 \\
$\mathrm{~N} 2-\mathrm{H} 2 B \cdots \mathrm{O} 1 W^{\text {iii }}$ & 0.83 & 2.30 & $3.063(2)$ & 153 \\
$\mathrm{~N} 4-\mathrm{H} 4 A \cdots \mathrm{O} 1 W^{\text {iv }}$ & 0.88 & 2.07 & $2.924(2)$ & 166 \\
$\mathrm{~N} 4-\mathrm{H} 4 B \cdots \mathrm{O} 1^{\mathrm{v}}$ & 0.96 & 2.09 & $3.015(2)$ & 161 \\
\hline
\end{tabular}

Symmetry codes: (i) $x,-y+\frac{3}{2}, z+\frac{1}{2}$; (ii) $-x+1,-y+1,-z+1$; (iii) $-x+2, y+\frac{1}{2}$, $-z+\frac{3}{2}$; (iv) $x-1,-y+\frac{3}{2}, z-\frac{1}{2}$; (v) $-x+1, y-\frac{1}{2},-z+\frac{3}{2}$.

\section{Compound (IV)}

Crystal data

$\mathrm{C}_{7} \mathrm{H}_{7} \mathrm{~N}_{3} \mathrm{O}_{3}$

$M_{r}=181.16$

Orthorhombic, $P 2_{1} 22_{1}$

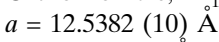

$b=4.9867$ (2) $\AA$

$c=12.8637$ (8) $\AA$

$V=804.29(9) \AA^{3}$

where $P=\left(F_{\mathrm{o}}^{2}+2 F_{\mathrm{c}}^{2}\right) / 3$

$(\Delta / \sigma)_{\max }<0.001$

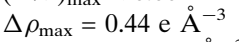

$\Delta \rho_{\min }=-0.36 \mathrm{e}^{-3}$

Data collection

Bruker-Nonius KappaCCD diffractometer

$\varphi$ and $\omega$ scans

Absorption correction: multi-scan

(SADABS; Sheldrick, 2003)

$T_{\min }=0.944, T_{\max }=0.991$

\section{Refinement}

Refinement on $F^{2}$

$R\left[F^{2}>2 \sigma\left(F^{2}\right)\right]=0.088$

$w R\left(F^{2}\right)=0.097$

$S=1.03$

1092 reflections

119 parameters

$\mathrm{H}$-atom parameters constrained
$Z=4$

$D_{x}=1.496 \mathrm{Mg} \mathrm{m}^{-3}$

Mo $K \alpha$ radiation

$\mu=0.12 \mathrm{~mm}^{-1}$

$T=120(2) \mathrm{K}$

Lath, brown

$0.63 \times 0.13 \times 0.08 \mathrm{~mm}$

11674 measured reflections 1092 independent reflections 713 reflections with $I>2 \sigma(I)$ $R_{\text {int }}=0.146$

$\theta_{\max }=27.5^{\circ}$

$w=1 /\left[\sigma^{2}\left(F_{\mathrm{o}}^{2}\right)+(0.0501 P)^{2}\right]$

where $P=\left(F_{\mathrm{o}}^{2}+2 F_{\mathrm{c}}^{2}\right) / 3$

$(\Delta / \sigma)_{\max }<0.001$

$\Delta \rho_{\max }=0.23{\mathrm{e} \AA^{-3}}^{-3}$

$\Delta \rho_{\min }=-0.19{\mathrm{e} \AA^{-3}}^{-3}$

Extinction correction: SHELXL97

Extinction coefficient: 0.040 (7) 
Table 4

Hydrogen-bond geometry $\left(\AA,^{\circ}\right)$ for (IV).

\begin{tabular}{lllll}
\hline$D-\mathrm{H} \cdots A$ & $D-\mathrm{H}$ & $\mathrm{H} \cdots A$ & $D \cdots A$ & $D-\mathrm{H} \cdots A$ \\
\hline $\mathrm{N} 1-\mathrm{H} 1 \cdots \mathrm{O} 1^{\mathrm{i}}$ & 0.95 & 1.92 & $2.815(3)$ & 157 \\
$\mathrm{~N} 2-\mathrm{H} 2 A \cdots \mathrm{O} 22^{\text {ii }}$ & 0.95 & 2.31 & $3.128(3)$ & 144 \\
$\mathrm{~N} 2-\mathrm{H} 2 B \cdots \mathrm{N} 2^{\mathrm{iii}}$ & 0.95 & 2.16 & $3.060(3)$ & 157 \\
$\mathrm{C} 3-\mathrm{H} 3 \cdots \mathrm{O} 1^{\text {iv }}$ & 0.95 & 2.43 & $3.269(4)$ & 148
\end{tabular}

Symmetry codes: (i) $x, y+1, z$; (ii) $x-\frac{1}{2},-y+\frac{1}{2},-z+1$; (iii) $-x+1, y-\frac{1}{2},-z+\frac{1}{2}$; (iv) $x+\frac{1}{2},-y+\frac{1}{2},-z+1$.

\section{Table 5}

Selected bond angles and torsion angles $\left(^{\circ}\right)$ for compounds (I)-(IV).

\begin{tabular}{lcccc}
\hline & $(\mathrm{I})$ & $(\mathrm{II})$ & $(\mathrm{III})$ & $(\mathrm{IV})$ \\
\hline $\mathrm{C} 2-\mathrm{C} 1-\mathrm{C} 7$ & $121.07(12)$ & $127.3(2)$ & $121.84(14)$ & $120.2(3)$ \\
$\mathrm{C} 6-\mathrm{C} 1-\mathrm{C} 7$ & $121.83(12)$ & $115.3(2)$ & $120.93(14)$ & $122.4(3)$ \\
$\mathrm{C} 1-\mathrm{C} 2-\mathrm{Cl} 2 / \mathrm{N} 21$ & $119.59(10)$ & $122.0(2)$ & $119.62(12)$ & $119.5(3)$ \\
$\mathrm{C} 3-\mathrm{C} 2-\mathrm{Cl} 2 / \mathrm{N} 21$ & $118.34(11)$ & $116.4(2)$ & $118.07(12)$ & $117.1(3)$ \\
$\mathrm{C} 1-\mathrm{C} 6-\mathrm{Cl} 6$ & $119.19(11)$ & - & - & - \\
$\mathrm{C} 5-\mathrm{C} 6-\mathrm{Cl} 6$ & $118.63(11)$ & - & - & - \\
$\mathrm{C} 2-\mathrm{C} 1-\mathrm{C} 7-\mathrm{O} 1$ & $-77.51(19)$ & $140.4(3)$ & $-63.0(2)$ & $-41.0(4)$ \\
$\mathrm{C} 2-\mathrm{C} 1-\mathrm{C} 7-\mathrm{N} 1$ & $103.00(15)$ & $-42.0(4)$ & $117.46(16)$ & $141.1(3)$ \\
$\mathrm{C} 1-\mathrm{C} 7-\mathrm{N} 1-\mathrm{N} 2$ & $176.00(12)$ & $179.3(2)$ & $176.31(14)$ & $178.4(2)$ \\
\hline
\end{tabular}

For compounds (I)-(IV), the space groups $P 2_{1} / n, P 2_{1} / c, P 2_{1} c$ and $P 2_{1} 2_{1} 2_{1}$, respectively, were uniquely assigned from the systematic absences. All $\mathrm{H}$ atoms were located in difference maps and then treated as riding atoms. $\mathrm{H}$ atoms bonded to $\mathrm{C}$ atoms were assigned $\mathrm{C}-\mathrm{H}$ distances of $0.95 \AA\left[U_{\text {iso }}(\mathrm{H})=1.2 U_{\mathrm{eq}}(\mathrm{C})\right]$. $\mathrm{H}$ atoms bonded to $\mathrm{N}$ or $\mathrm{O}$ atoms were permitted to ride at the $\mathrm{X}-\mathrm{H}$ distances deduced from the difference maps, giving $\mathrm{N}-\mathrm{H}$ distances of $0.83-0.96 \AA$ $\left[U_{\text {iso }}(\mathrm{H})=1.2 U_{\text {eq }}(\mathrm{N})\right]$ and $\mathrm{O}-\mathrm{H}$ distances of $0.84-0.87 \AA\left[U_{\text {iso }}(\mathrm{H})=\right.$ $\left.1.5 U_{\mathrm{eq}}(\mathrm{O})\right]$. The crystals of compound (IV) were consistently of poor quality, and this is reflected in the high merging index and the high final $R$ values. In the absence of significant resonant scattering it was not possible to determine the absolute configuration of the molecules in the crystal of (IV) selected for data collection; accordingly, the Friedel equivalent reflections were merged prior to the final refinements.

Data collection: KappaCCD Server Software (Nonius, 1997) for (I); COLLECT (Hooft, 1999) for (II), (III) and (IV). Cell refinement: $D E N Z O-S M N$ (Otwinowski \& Minor, 1997) for (I); DENZO
(Otwinowski \& Minor, 1997) and COLLECT for (II), (III) and (IV). Data reduction: $D E N Z O-S M N$ for (I); DENZO and COLLECT for (II), (III) and (IV). Program(s) used to solve structure: SHELXS97 (Sheldrick, 1997) for (I); OSCAIL (McArdle, 2003) and SHELXS97 (Sheldrick, 1997) for (II), (III) and (IV). Program(s) used to refine structure: SHELXL97 (Sheldrick, 1997) for (I); OSCAIL and SHELXL97 (Sheldrick, 1997) for (II), (III) and (IV). For all compounds, molecular graphics: PLATON (Spek, 2003); software used to prepare material for publication: SHELXL97 and PRPKAPPA (Ferguson, 1999).

X-ray data were collected at the EPSRC National Crystallography Service, University of Southampton, England; the authors thank the staff of the Service for all their help and advice. JLW thanks CNPq and FAPERJ for financial support.

Supplementary data for this paper are available from the IUCr electronic archives (Reference: GG3041). Services for accessing these data are described at the back of the journal.

\section{References}

Allen, F. H. (2002). Acta Cryst. B58, 380-388.

Allen, F. H., Kennard, O., Watson, D. G., Brammer, L., Orpen, A. G. \& Taylor, R. (1987). J. Chem. Soc. Perkin Trans. 2, pp. S1-19.

Bernstein, J., Davis, R. E., Shimoni, L. \& Chang, N.-L. (1995). Angew. Chem. Int. Ed. Engl. 34, 1555-1573.

Ferguson, G. (1999). PRPKAPPA. University of Guelph, Canada.

Hooft, R. W. W. (1999). COLLECT. Nonius BV, Delft, The Netherlands.

Kallel, A., Amor, B. H., Svoboda, I. \& Fuess, H. (1992). Z. Kristallogr. 198, 137-138.

McArdle, P. (2003). OSCAIL for Windows. Version 10. Crystallography Centre, Chemistry Department, NUI Galway, Ireland.

Nonius (1997). KappaCCD Server Software. Windows 3.11 Version. Nonius BV, Delft, The Netherlands.

Otwinowski, Z. \& Minor, W. (1997). Methods in Enzymology, Vol. 276, Macromolecular Crystallography, Part A, edited by C. W. Carter Jr \& R. M. Sweet, pp. 307-326. New York: Academic Press.

Ratajczak, H., Baran, J., Barnes, A. J., Barycki, J., Debrus, S., Latajka, Z., May, M. \& Pietraszko, A. (2001). J. Mol. Struct. 596, 17-23.

Saraogi, I., Mruthyunjayaswamy, B. H. M., Ijare, O. B., Jadegoud, Y. \& Guru Row, T. N. (2002). Acta Cryst. E58, o1341-o1342.

Sheldrick, G. M. (1997). SHELXS97 and SHELXL97. University of Göttingen, Germany.

Sheldrick, G. M. (2003). SADABS. Version 2.10. University of Göttingen, Germany.

Spek, A. L. (2003). J. Appl. Cryst. 36, 7-13. 